University of Nebraska - Lincoln

DigitalCommons@University of Nebraska - Lincoln

Marketing Department Faculty Publications

Marketing Department (CBA)

2008

\title{
Anomie and the Marketing Function: The Role of Control Mechanisms
}

Amit Saini

University of Nebraska - Lincoln, asaini2@unl.edu

Mike Krush

University of Nebraska - Lincoln, mkrush@unlserve.unl.edu

Jean L. Johnson

Washington State University, Pullman,WA, johnsonjl@wsu.edu

Follow this and additional works at: https://digitalcommons.unl.edu/marketingfacpub

Part of the Marketing Commons

Saini, Amit; Krush, Mike; and Johnson, Jean L., "Anomie and the Marketing Function: The Role of Control Mechanisms" (2008). Marketing Department Faculty Publications. 5.

https://digitalcommons.unl.edu/marketingfacpub/5

This Article is brought to you for free and open access by the Marketing Department (CBA) at DigitalCommons@University of Nebraska - Lincoln. It has been accepted for inclusion in Marketing Department Faculty Publications by an authorized administrator of DigitalCommons@University of Nebraska - Lincoln. 


\title{
Anomie and the Marketing Function: The Role of Control Mechanisms
}

\author{
Amit Saini, ${ }^{*}$ Mike Krush,* and Jean L. Johnson**

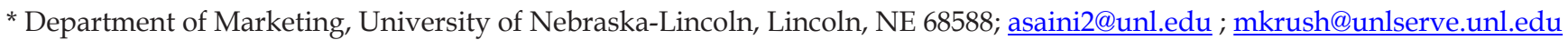 \\ ** Department of Marketing, Washington State University, Pullman, WA 99164; johnsonj1@wsu.edu \\ Corresponding author - A. Saini
}

\begin{abstract}
The theoretical notion of anomie is used to examine the impact of top management's control mechanisms on the environment of the marketing function. Based on a literature review and in-depth field interviews with marketing managers in diverse industries, a conceptual model is proposed that incorporates the two managerial control mechanisms, viz. output and process control, and relates their distinctive influence to anomie in the marketing function. Three contingency variables, i.e., resource scarcity, power, and ethics codification, are proposed to moderate the relationship between control mechanisms and anomie. The authors also argue for the link between anomic environments and the propensity of unethical marketing practices to occur. Theoretical and managerial implications of the proposed conceptual model are discussed.
\end{abstract}

Keywords: anomie, ethics codification, control mechanisms, marketing function, normlessness, output control, power, process control, resource scarcity

\section{Introduction}

Of all the divisions in a business organization, the marketing function is the one most often charged with harboring unethical practices (Akaah and Riordan, 1990; Baumhart, 1961; Brenner and Molander, 1977; Tsalikis and Fritzsche, 1989). Past research has examined a variety of avenues in the practice of marketing where questionable ethical behavior may occur. For instance, ethical questions have been raised in market research (Hunt et al., 1984; Nantel and Weeks, 1996; Tybout and Zaltman, 1974), salesforce supervision (Hunt and Vasquez-Parraga, 1993), pricing management (Nantel and Weeks, 1996), target marketing (Smith and Cooper-Martin, 1997), and product and service management (Nantel and Weeks, 1996). ${ }^{1}$ Scholars have argued that marketing gathers more notoriety, because unlike other functions such as accounting, finance, or operations, marketing performs a boundary-spanning role for the organization and is therefore more likely to be exposed to environmental pressures to deviate (Ferrell and Gresham, 1985). These pressures could emanate from suppliers, competitors, and shifting consumer tastes, among other sources. While firms may not have any sizeable influence on these external pressures, they can, however, shape the environment of the marketing function to empower executives with greater ethical sensitivity.

By and large, ethical decision making by the marketing team is influenced by three types of factors: individual characteristics, organizational characteristics, and environmental factors (Leigh and Murphy, 1999). Scholars have used a variety of theoretical frameworks to address these factors, including: frameworks based on moral philosophies (Laczniak and Murphy, 1991), contingency models of ethical behavior (Ferrell and Gresham, 1985), models based on individual deontological and teleological evaluations (Hunt and Vitell, 1986), examinations of cross-cultural influences (Giacobbe and Segal, 2000), analyses of the nature of the decision situation (Lund, 2000), and the integration of ethics into marketing strategy (Robin and Reidenbach, 1987), among others. All these approaches have made significant contributions to the discussion on ethics in marketing; however, examination of organizational characteristics necessitates further research attention, as these are the only factors that are truly under the control of the firm's top-management team (Ferrell and Gresham, 1985; Leigh and Murphy, 1999; Vardi, 2001; Vardi and Wiener, 1996). 
The fundamental question for a firm's senior management remains: how to avoid creating conditions in the marketing function that could lead to ethical transgressions? Scholars and practitioners have answered this in myriad ways. Some have recommended formal corporate policies and codes of conduct (Murphy, 1995), while others have argued that marketing's strategic planning process should integrate ethical values from the very inception (Robin and Reidenbach, 1987). We argue that, in addition to these recommendations, one needs to address the root causes that may create an environment ripe for unethical practices in the marketing function. We, therefore, propose that a crucial piece of the ethics puzzle lies in understanding how the top management chooses to control the marketing function and in examining the unintended ramifications of the chosen control mechanism. We synthesize our review of the literature with multiple field interviews of marketing managers from diverse industries to conceptualize a contingency model. In the contingency model, we examine the potential effects of two of the most commonly used control mechanisms, viz. output and process control (Jaworski, 1988) on the environment of the marketing function. To describe the environment of the marketing function, we use the theory of anomie (Merton, 1964, 1968). Anomie is a situational condition characterized by normlessness and social disequilibrium that sets the stage for deviant behavior. In addition, we examine the impact of three moderating factors, resource scarcity, power, and ethicscodification,onthecontrolmechanism-anomie relationship.

We make multiple contributions to the academic literature and managerial practice. First, we address anomie in marketing at the functional silo level, moving the discussion beyond its earlier applications in sales management. Second, we use a sociological approach to anomie that analyzes the environment of the marketing function at a structural level. This is a distinctly different approach from previous examinations that utilized the psychological notion of anomie and targeted the individual level. Third, we identify and conceptualize the dynamics of top-management control of marketing as a critical antecedent to the creation of anomie. Finally, we identify conditions that could exacerbate or abate the control-mechanism-anomie relationship. In terms of implications for practice, we argue that scrutinizing the marketing function through the anomie lens can help firms understand the nature of the environment that causes the proliferation of unethical marketing practices. Armed with such an understanding, managers can then work to minimize anomie and therefore reduce the chances of ethical transgressions.

In the following sections, we first provide an overview of ethically questionable practices in marketing followed by a description of our data collection. Second, we introduce the theoretical notion of anomie and demonstrate the appropriateness for its applicability to the context of a marketing function. Third, we discuss control mechanisms and present our propositions on the effects of output and process control on anomie in the marketing function; further propositions are argued with contingency variables as moderators. In the final sections of the article, we offer a discussion of the theoretical and managerial implications of our work.

\section{Ethics and the marketing function}

While there is no universal guideline for what constitutes ethical conduct in marketing practice (Ferrell and Gresham, 1985), there is an understated expectation that responsible marketing should not intentionally violate social contracts or cause harm to any of the parties involved. We, therefore, define unethical marketing practices as intentional decisions and actions that violate social contracts with, and result in harm to, internal or external constituents of the marketing function (Cohen, 1993; Hunt et al., 1989). For instance, misrepresenting products, services, and information (Hunt et al., 1984); promoting unneeded products and services (Blankenship, 1964; Hunt and Vasquez-Parraga, 1993); or offering financial inducements to secure an advantaged position (Blankenship, 1964) would all constitute ethically questionable practices.

Marketing executives often get their cues on ethical standards from the environment of the marketing function. Past research has addressed the issue of ethics and organizational environment (Bommer et al., 1987; Jones, 1991; Trevino et al., 1998) and has underscored the fact that the corporate context is a critical determinant of the ethical standards of marketing managers (Leigh and Murphy, 1999; Robin and Reidenbach, 1987). Additionally, research shows that organizational sub-units construct their 
own values and norms that are distinct from that of the larger organization (Vardi, 2001). Consequently individuals within a department or function may refer to the sub-unit's value system for behavioral cues and direction (Schein, 1984). Thus marketing as a sub-unit may have its own idiosyncratic culture, norms, and predominant values (Schneider and Rentsch, 1988). This environment of the marketing function is a crucial piece of the ethics puzzle, because it provides the setting for either abating or fostering ethically questionable practices (Leigh and Murphy, 1999).

While various theoretical approaches have been used in the past to capture the environment of a sub-unit, e.g., culture ("patterns of shared values and beliefs"; Deshpande and Webster, 1989, p. 4) or climate ("member's perceptions about the extent to which the organization is currently fulfilling their expectations"; Deshpande and Webster, 1989, p. 5), our approach here is to utilize a theoretical lens that captures the sociological underpinnings of unethical behavior. We therefore use the theoretical notion of anomie (Durkheim, [1897]/1951; Merton, 1968) to describe the environment of the marketing function and to examine this environment's intervening role between the choice of control mechanisms and the resulting unethical practices in marketing decision making.

\section{Data collection and analysis}

Given our aim of bringing conceptual understanding to a phenomenon, we employ a pragmatic and pluralistic research approach (Creswell and Plano Clark, 2007), rather than a purely positivistic or interpretive one. Specifically, our approach utilizes two methods to develop conceptual understanding - a literature review and qualitative research through in-depth interviews. This approach has been found to be useful in other contexts for examining the marketing function (Kohli and Jaworski, 1990; Workman et al., 1998). Specifically, it allows us to synthesize our qualitative findings with past research and theory. Through the combined use of qualitative data and the literature, we present propositions and arguments for the same. In addition, the pluralistic design provides us with a means to reconstruct theory (Burawoy, 1991) and capture the dynamic nature of the anomie phenomenon.
Our qualitative interviews were semi-structured and composed entirely of open-ended questions, with the intent of allowing the participants to expand and explain their thoughts and experiences. The length of the interviews ranged from approximately $30 \mathrm{~min}$ to an hour and a half. Purposeful sampling was utilized (Creswell and Plano Clark, 2007) and resulted in six individual interviews. The respondents were senior-level marketing officials, with titles ranging from Vice President-Marketing to Brand Manager, and employed in diverse industries (Software, Pharma, Consumer Goods, etc.). On average, the respondents possessed 11 years of work experience and were evenly split on gender ( 3 males and $3 \mathrm{fe}-$ males). The interviews were initially taped, and later transcribed and analyzed in the phenomenological tradition (Moustakas, 1994). This process consists of bracketing personal experiences; coding the database; developing significant statements; grouping together the statements into meaning units, themes, and premises.

\section{Anomie and the marketing function}

The theory of anomie provides a useful theoretical framework to examine unethical behavior from a sociological and/or a psychological perspective. In this paper, we utilize Robert Merton's original theory of social structure and anomie (Merton, 1964). This theory provides a useful lens to address the conditions that may lead a marketing function toward unethical marketing practices. In this theory, anomie is defined as a condition of "normlessness or social disequilibrium where the rules once governing conduct have lost their savor or force" (Merton, 1964, p. 226).

While the thrust of our argument advocates the value of using Merton's theory of anomie to describe the marketing function's internal environment, we also believe it is necessary to outline the distinctions between the sociological and psychological examinations of anomie. Attention to these distinctions is necessary as scholars have noted that two sources of confusion often surround the study of anomie: (a) a misunderstanding exists in the differences between Merton's theory of anomie and Merton's theory of strain (Featherstone and Deflem, 2003) and, (b) a blurring of lines has evolved between Merton's strain 


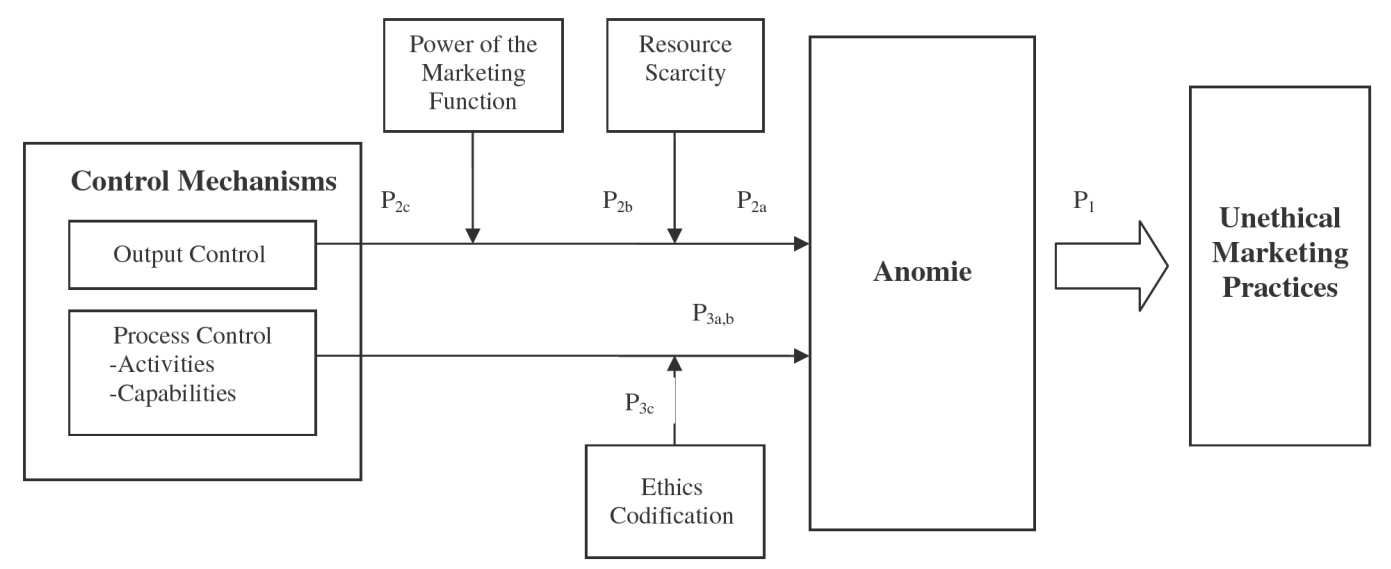

Figure 1. A model of antecedents and consequences of anomie in the marketing function.

theory and the characterization of anomy or anomia in the psychology literature (Orru, 1987). As these distinctions are central to understanding our contributions to the ethics and marketing literature, we now delineate them (Figure 1). The sociological stream of anomie is most often credited to Durkheim ([1897]/1951). Taking a sociological and structural perspective, Durkheim's ([1897]/1951) work focused on the link between environmental conditions or social causes and the patterns of deviant acts such as crime or suicide. Durkheim ([1897]/1951) purported that human nature was relatively invariant; hence, the social environment provided greater explanatory power of behavior than a psychological understanding of it.

Merton $(1964,1968)$ built upon Durkheim's work in an effort to explain how the rates of deviant behavior may vary in different social structures. Merton (1968) developed a systematic framework that outlined two structures to analyze a social system, a cultural structure and a social structure. Merton (1968) argued that the two structural conditions influence individual behavioral processes and interactions within the social institution. The first attribute, the cultural structure, comprises two elements - the goals communicated by the social institution and the institutionalized norms and procedures that provide direction in attaining such goals (Merton, 1968). The second, the social structure, focuses on the various relationships that individuals are inherently involved in within any group or society (Merton, 1968).
Using these two structures as a framework to examine social systems, Merton (1968) outlined two theories. Merton's first theory, the theory of anomie, primarily uses the cultural structure (i.e., the universal goals and the normative means to attain the goals) to examine a social system. When the goals emphasized by an institution's culture are prioritized over the standard, accepted procedures to reach the goals, a disjuncture or imbalance occurs within the cultural structure. Merton (1968) purported the environment resulting from this disjuncture is best described as anomie, or an atmosphere ripe with normlessness and disregard for normative rules and procedures. The conditions of anomie would be further enhanced when these normative procedures are effectively disregarded to reach the culturally approved goal (Merton, 1968). Merton (1968) suggested this form of anomie occurs within the U.S. society when the cultural values of materialism and monetary success outweigh the normative procedures to attain such goals. Hence, Merton's theory is notable for two reasons. First it is an aggregate-level analysis of a social system (Baumer, 2007). Second, it uses these aggregate level structures to help in describing the variation in rates of deviation across collectivities, such as groups, departments, firms, and societies (Baumer, 2007).

Merton's second theory, the theory of strain, is often confused or intermingled with his theory of anomie. However, sociology scholars maintain that each theory is distinct (Baumer, 2007; Featherstone and Deflem, 2003). Unlike Merton's (1968) theory 
of anomie, the theory of strain incorporates both the cultural and social structures of a social system. Its goal is to explain the pressures that propel an individual toward using illegitimate means to attain cultural goals. According to Merton (1968), when the cultural and social structures are not in equilibrium, the individual feels a strain. For instance, an individual may feel strain in American society when the cultural goals, such as material success, are uniformly applied and generally accepted by everyone in society; however, the social structure, such as the class structure, does not uniformly distribute the means to attain these goals (Messner, 2003).

When faced by an impediment toward goal achievement, the individual feels a sense of frustration (Berkowitz, 1962), dissatisfaction, and pressure (Agnew et al., 1996). In society, this frustration may result when one's achieved status or class falls short of the culture's ascribed status or class (Jackson and Burke, 1965; Stinchcombe, 1964). In a business context, frustration and dissatisfaction may result when an individual or department pursues corporate objectives, but does not have access to the necessary financial, temporal, or human resources to attain the goal (Poveda, 1994). Hence, the notion of frustration, negative affect, and dissatisfaction is central to Merton's and others' theories of strain (Agnew et al., 1996; Cloward and Ohlin, 1960). However, it should be noted that frustration and dissatisfaction do not erratically or immediately occur. Instead, frustration often occurs in an incremental, evolutionary manner and the response of others within the social environment is a critical element in this process (Cohen, 1965).

To manage the pressure and frustration created by the environment, the individual may choose among five distinct responses or social roles, including roles that would motivate the individual to act in a deviant manner (Merton, 1968). These social roles are based on the acceptance of, rejection of or substitution of the current cultural goals and institutionalized means (Merton, 1968). These adaptations include the acceptance of means and goals (e.g., conformity), the acceptance of goals and rejection of means (e.g., innovation), the rejection of goals and an acceptance of means (e.g., ritualism), the rejection of both goals and means (e.g., retreatism), or a complete replacement of goals and means (e.g., rebellion) (Merton, 1968).
Summarily, the theory of strain provides a structural explanation of the processes that link a situation (i.e., goal impediment created by a structural imbalance) with one's motivation to act (i.e., commit an act of deviance) (Baumer, 2007; Featherstone and Deflem, 2003). At a broad level, this situationindividual approach resembles the framework widely used in social psychology. The commonality in framework may also explain the co-mingling of theories and vocabulary that has evolved between (a) Merton's (1968) structural theory of strain and (b) individual-level approaches in psychology, such as anomy and anomia, that describe an individual's "social malintegration" (Srole, 1956, p. 712) and "the breakdown of the individual's sense of attachment to society" (MacIver, 1950, p. 84) due to an imbalance within a social system (Orru, 1987). In addition, scholars have mixed the sociological and psychological theories over the years. For instance, Hirschi's Causes for Delinquency gradually altered strain theory from a structural-level analysis toward a more individual-level analysis (Burton Jr. and Cullen, 1992), and researchers have further blurred the distinction by referring to anomie and anomia interchangeably in studies of deviance including that of white-collar crime (Krause, 2002; Poveda, 1994).

The shift away from sociology's "structural determinants of anomie toward the effects of a psychological conditions on other individual attitudes and condition" (Orru, 1987, p. 127) was also propelled by works in psychology by MacIver (1950) and Srole (1956). The psychological stream of anomie, called anomy (MacIver, 1950) or anomia (Srole, 1956), is squarely situated as an analysis conducted at the individual level. One need only examine MacIver's definition of anomy, "the breakdown of the individual's sense of attachment to society" (p. 84), or Srole's (1956) instrument that measures anomia, the "self-to-other alienation" (p. 711), to understand psychological approaches are based on individual rather than structural-level analyses. In related research, empirical studies of anomie within marketing, ethics, and management have been conducted at the individual level of analysis by using the Srole scale of anomia or a similar individual-level measurement instrument. These studies have examined abuses of retail-return policies by consumers (Rosenbaum and Kuntze, 2003), reactions to customer fraud by store employees (Ca- 
ruana et al., 2001), actions such as cheating by undergraduate business school students (Caruana et al., 2000, 2001), and assessments of anomia inside and outside the workplace (Tsahuridu, 2006).

In contrast to the individual-level approach used by previous studies, our approach to examining anomie is different. Specifically, we return to anomie's sociological origins and use Merton's (1968) theory of anomie to conceive of an analysis at the structural level. This structural-level theory (Burton Jr. and Cullen, 1992) provides a unique theoretical basis for understanding social systems, such as organizations and marketing departments, that possess a distinct culture of their own (Deshpande and Webster, 1989; Ghoshal and Moran, 1996) which transmits goals and sets normative standards to attain these goals. The structural approach provided by the theory of anomie has been reaffirmed by scholars who suggest it "remains a valuable perspective for the study of deviance in society." (Featherstone and Deflem, 2003, p. 485) This approach is also noteworthy in three final respects. First, it adds to the paucity of research on anomie that has been noted by scholars within management (Caruana et al., 2001), organizations (Tsahuridu, 2006), and marketing (Rosenbaum and Kuntze, 2003). Second, our approach is applied to a unique milieu. Whereas previous discussions have focused on retail-sales settings (Caruana et al., 2001), undergraduate business schools (Caruana et al., 2000, 2001), and workplaces in general (Tsahuridu, 2006), we examine the hub of marketing activity, the marketing department. Finally, this approach builds upon previous research on anomie. This examination studies anomie within a functional department, thereby heeding Tsahuridu's (2006) call for anomie research aimed at "different organizational levels" (p. 171), and also meeting Caruana et al.'s (2001) recommendation that future research efforts study additional relationships that potentially explain a greater amount of the variance associated with anomie.

There are multiple reasons why the notion of anomie is particularly well suited for studying ethics in the marketing function. First, the theory's unit of analysis is a collective, which is applicable to the organization and an organizational sub-unit. Second, the theory explains the impact of social structure on behavior. Thus, anomie provides a means to characterize the social structure of an organiza- tion and predict an environment that influences potential behavior. Finally, the theory represents anomie as a dynamic state or condition, which allows us to understand a variety of deviant behaviors. We now explicate these three reasons to demonstrate the suitability of the theory to our context.

(1) The unit of analysis. Given anomie's origins in sociology, its unit of analysis focuses on the collective and not the individual. Specifically, the theoretical notion of anomie was propounded to analyze the patterns of relationships and behaviors within social units and institutions. This collective perspective has allowed researchers to apply the theory to a range of social units, including the American society (Merton, 1968; Messner and Rosenfeld, 1997), various organizational contexts (Cohen, 1995), cohorts within a population (Lee and Bartkowski, 2004), corporate mergers and acquisitions (Mansfield, 2004), and communities (Fullilove et al., 1998).

(2) Impact of social structure on behavior. Organizations manage their structural conditions through various control mechanisms that define organizational goals and monitor behavioral progress toward the emphasized goals (Ouchi, 1977). These control mechanisms create a pervasive environment that impacts multiple aspects of organizational life including behavior (Cohen, 1995). The theory of anomie provides a means to identify distinct structural conditions under such control mechanisms, the environment formed from the combination of these structural conditions, and the behavior resulting from such an environment. Thus, it serves as a valuable guide in defining the structural circumstances that may lead to deviant behaviors within the organization's sub-units (Cohen, 1995).

(3) Explanatory power. The theory also provides a means to explain a wide range of unethical marketing practices. Merton's (1968) representation of anomie as a state or a condition is intrinsically dynamic, i.e., anomie is influenced by its immediate context, and can change or even reverse (Smith, 1998). This 
dynamic nature allows the theory to explain a wide range of behaviors under high or low levels of anomie, by examining the equilibrium between institutionalized goals and means.

\section{Anomie and ethics in marketing}

We suggest that unethical marketing practices gain a fertile ground when economic goals, such as profit, market share, earnings per share, or stock price, are overwhelmingly prioritized, or when the communicated and accepted goals are simply unattainable under the prevalent conditions or resources within the marketing function. Specifically, a disjuncture occurs between the social system's goals and the means to attain these goals. Under such conditions the marketing function is faced with structural characteristics that are in imbalance. This imbalance creates a departmental environment that can be characterized as anomic.

Merton (1968) purports that under anomic conditions, the frequency of departures from accepted norms increases. This is largely because anomie promotes an environment in which the firm's prescribed goals are placed ahead of the normative means to achieve them (Cohen, 1993). When operating in this environment, decision makers in the marketing function may begin to disregard standards of legitimate marketing practice (as they observe others in marketing do the same), and in a zeal to capture the market at any cost, may simply lose their drive to act ethically (Cohen, 1993). The slippery slope from anomic environment to unethical marketing practices was described by a number of our respondents. They were not only cognizant of such an environment, but also aware of its outcome:

people are ... the product of their environment. So if they're observing, particular patterns of behavior or see things going on, then they are more inclined to say, 'that must be acceptable here, and now I've got an opportunity to', or.. 'that must mean that it's okay if I do this stuff'. And so they start to cut corners, and they start to make these bad decisions, and they're basically, replicating what they've seen.

-Vice President, Medical Technology and Equipment
The marketing landscape is replete with instances of such consequences. From the brand manager's internal push of a premeditated and predetermined market research study to gain a higher budget, to misrepresenting products, services, and information to clients (Hunt et al., 1984); to slipping new products past federal inspections (Cohen, 1993) - as the marketing function's environment becomes more anomic, the propensity for unethical marketing practices increases. Thus, we propose:

P1: A positive relationship exists between the level of anomie in the marketing function and the likelihood of unethical marketing practices to occur.

The level of anomie in the marketing function could be affected by many factors. We argue that it is particularly influenced by how the top management chooses to control the marketing function. One of the key decisions taken by a firm's topmanagement team is to settle on how the various functional sub-units will be controlled. By selecting a particular way to control each functional subunit, the top management communicates, both explicitly and implicitly, the goals, means, rewards, and punishments that come with the territory. It is, therefore, critical to examine the impact that control mechanisms have on the extent of anomie in the marketing function.

\section{Control of the marketing function}

Of all the functional silos in a firm, marketing is perhaps the most closely watched and scrutinized function by the top management (Kumar, 2004). There are multiple reasons for this. First, marketing is the primary engine of financial growth for the firm and is almost singularly responsible for sales, margins, profits, and earnings. This pressure to deliver the financial bottom-line on a quarterly basis is particularly acute for marketing functions of publicly traded firms (Trostel and Nichols, 1982). Second, marketing is a considerable cost center for the firm. With product development, promotion, and distribution expenses amounting to a large proportion of the annual budgets, marketing instantly attracts top-management attention (Srivastava et al., 1998). Finally, decisions taken by a firm's 
marketing team have strong ramifications for the firm's future. Decisions on branding, positioning, and public relations directly impact the firm's corporate reputation and competitive advantage. Topmanagement teams, therefore, feel the need to actively control the marketing function.

Top management's choice of a mechanism to control the marketing function is largely dependent on the firm's corporate goals, its structural configuration, and its market conditions. By and large, control mechanisms come in two hues: (1) control of marketing outputs, and (2) control of marketing personnel and processes (Jaworski, 1988). Where the former (known as output control) focuses on controlling the specific outcomes of marketing activities, the latter (referred to as process control) is meant to control the processes, actions, and capabilities of marketing individuals (Challagalla and Shervani, 1996; Jaworski, 1988; Ramaswami, 1996). We propose that each of the two types of control mechanisms has a noteworthy and distinctive impact on anomie in the marketing function.

\section{Output control}

Output control is, by and large, operationalized by setting a performance standard (e.g., target market share), evaluating the results (e.g., achieved market share) against the standard, and taking corrective action in the event of a discrepancy between the two (Jaworski, 1988). Since marketing outcomes are crucial to the financial survival of the firm, controlling the output of the marketing function is deemed critical by top management (Kumar, 2004). Consequently, strong emphasis is placed on strict outcome measures, such as market share, profits, margins, inventory levels, brand equity, customer lifetime value, and other financial assessments of marketing productivity. Additionally, scholars also highlight that intermediate non-financial outcomes such as customer attitudes and satisfaction deserve constant attention as well (Rust et al., 2004).

Given the enhanced focus on marketing's accountability, top management is prone to use output control of marketing productivity as a mechanism to manage the marketing function; research in the sales context shows that output control is known to enable clear goal setting and explicit performance standards, which minimize the adverse effects of role conflict and role ambiguity (Ramaswami, 1996). However, output control, if used predominantly, does not involve the specification of procedures that the marketing function should follow to reach the financial or non-financial goals or objectives. Consequently, marketing managers are left with considerable strategic and operational freedom to pursue the paths to reach their goals.

The combination of high-pressure bottom-line management and operational freedom can have dysfunctional consequences for the environment of the marketing function. For instance, scholars have noted that the predominant use of output control by the top management can lead to increased dysfunctional behavior by the marketing team (Jaworski, 1988). The dysfunctional behaviors include: gaming (i.e., behavior that looks good in terms of control system metrics but is otherwise dysfunctional for the firm, e.g., re-defining the product-market space to show a high market share), smoothing (i.e., data manipulation to provide a consistent pattern of information such as sales figures, costs etc.), focusing (e.g., data manipulation to enhance or degrade specific control information, such as branch office performance), and invalid reporting (i.e., intentionally presenting inaccurate information, such as budget overestimates) (Jaworski, 1988). One of the key reasons for such dysfunction under output control is that, where on the one hand the top management insists on performance accountability, on the other it leaves the choices of marketing activities, processes, and decisions almost entirely to the marketing team. Consequently, the marketing team may potentially follow the most efficient paths toward goal attainment rather than utilize normative means. Similar evidence has been found in the context of opportunistic behavior of salespeople. Salespeople under output control have been found to engage in opportunistic behaviors to construe a positive impression on their supervisors (Ramaswami, 2002). As was noted by our respondents:

Our incentives [are] very individual based .... If you could break a rule and you get something done and you don't get caught for it, you're going to get the benefit of it. If you don't break the rule and you don't get something accomplished, 
you're going to pay for it .... you won't advance as quickly ....

-Brand Manager, Consumer Packaged Goods

And if a salesman thinks he has no chance of making this quarter, he will hold sales until next quarter when he might think he has a better chance ... that's absolutely a pervasive industry practice.

-Brand Manager, Pharmaceuticals

While output control, used predominantly, does provide key goalposts for the marketing function, it often leaves the choice of the means to the marketing team. According to anomie theory, as cultural goals within a social system are prioritized over the means to attain those goals, there is potential for a disjuncture or an imbalance to occur within the social system. This imbalance is created when the drive to reach the goals creates a disregard for or diminishes the belief to follow the normative means to reach them. When a disjuncture between the cultural goals and means occurs, we would expect a greater propensity toward anomie (Cohen, 1995). Therefore, we propose:

P2a: A positive relationship exists between the level of output control used in managing the marketing function and the level of anomie within the marketing department.

The impact of output control on anomie can be more pronounced under certain conditions. We identify these contingency variables as (a) resource scarcity, and (b) power of the marketing function, and develop propositions about each variable's role in moderating the effects of output control on anomie.

\section{Output control and resource scarcity}

The marketing function is resource intensive and frequently demands organizational resources. Since the costs associated with marketing activities constitute a large portion of a firm's financial outlay, increasingly marketing functions face greater accountability for resources expended in any given financial year (Srivastava et al., 1998). A key reason for this is the time lag between most marketing expenditures and the relative payoffs from the investment. For instance, advertis- ing and other branding exercises deplete a firm's working capital in the short term and may not deliver expected rewards (such as sales, market share, or brand image) until much later. Therefore, a firm routinely faces trade-offs in deciding how much of its resources should be deployed to marketing activities. Sometimes, the firm's priorities, strategies, and environmental dynamics may necessitate that organizational resources, normally devoted to the marketing function, may be reduced or even withheld. For instance, to offset higher-than-expected commodity input costs, the firm may reduce the marketing function's advertising and promotion budget. Or as our respondents noted:

... if you have more resources, usually you can get more stuff done, so you don't have to always cut the corners...

-Brand Manager, Consumer Packaged Goods

... they'll [marketing personnel] tell you because they don't have the [resources], that they're just doing whatever it takes, and they're not going to worry about [certain] ethical issue(s) ... they always have [the excuse] in their back pocket, 'well, it's because I don't have enough resources', or ' I don't have enough staff, so I'm just gonna do it, and then they [marketing management] can't get mad at me'

\section{-Regional Marketing Director, Healthcare}

Under such a condition of resource scarcity, the marketing function may find itself facing dual challenges - high expectations to meet the goals inherent in the firm's output control system and institutional constraints that hinder the means to reach those goals. The constraint on resources combined with a greater emphasis on efficiently reaching the expected goals may propel the function's dismissal of normative means. Consequently, marketing executives are likely to feel encouraged to reach their goals through any means possible, leaving a larger door open for anomic conditions to prevail. Thus, we propose:

P2b: As the resources allocated for marketing in the firm go down, the greater is the impact of output control on anomie in the marketing function. 


\section{Output control and power of the marketing function}

We propose that the relative power of the marketing function in the organization moderates the impact of output control on anomie. Since an organization is a coalition of competing interests (Anderson, 1982), power of the marketing function is defined as the relative amount of influence that the functional group can exercise over strategic issues in the firm during a specified time period (Workman et al., 1998). Power of the marketing function depends on a number of things: centrality (how central and essential are marketing activities to the organization), uncertainty coping (to what extent can marketing buffer the organization by coping with uncertainty), substitutability (how non-substitutable are marketing activities to the firm), and financial control (to what extent can marketing control the size and spending of its budget) (Hickson et al., 1971; Starr and Bloom, 1994). There is a lot of variation in the relative power of the marketing function across different industries and types of firms. For instance, the marketing function has been found to have limited relevance in technology-driven and other industrial companies, as opposed to having higher relevance in consumer goods companies (Homburg et al., 1999).

Marketing functions that are powerful and influential within their respective firms have more leverage in terms of the means they can utilize to reach their goals. If a sub-unit is a powerful constituent in the organization, it is hard to question the legitimacy of its ways and means. Thus, power provides the marketing function with more wherewithal and opportunities to dismiss normative means, and to do as it pleases. Our respondents confirmed the influence of power toward greater autonomy of marketing actions:

... the more power that the marketing group has to make changes, to pursue their short term targets, the more they'll [use it]. I don't think that the value of the future outweighs, at least in our structure, the short term value of the cash bonus.

-Brand Manager, Pharmaceuticals

From the literature and our respondents' comments, it appears that a powerful, and hence, unrestrained marketing function is more likely to fol- low the most efficient paths to reaching its goals, with a lesser concern for the legality or ethicality of those paths. Therefore, we conjecture:

P2c: As the power of the marketing function in the firm increases, the greater is the impact of output control on anomie in the marketing function.

\section{Process control}

Process control mechanisms refer to the top management directing both the activities and capabilities of the marketing team. Supportive evidence for process control has also been found in the context of ethical behavior of salespeople. Research in the sales context indicates that control systems do have an impact on ethical decision making (Verbeke et al., 1996) and that salesforce operating under process control behave more ethically than those under output control (Robertson and Anderson, 1993; Roma'n and Munuera, 2005). Further, research on salesforce supervision suggests that process control not only leads to salespeople being more competent, committed, and motivated, but also helps foster an organizational culture that promotes deontologically ethical behavior (Hunt and Vasquez-Parraga, 1993). Overall, one can expect similar responses to process control in the departmental context of marketing function.

Since process control is directed at both activities and capabilities of the personnel involved, the marketing team is better prepared to handle market pressure than it can under output control. The market pressure on the marketing function can come from numerous constituents. The pressure could stem from competition, changing trends in the marketplace, investors and analysts (for publicly traded firms), regulating agencies, suppliers, or retailers. Under pressure, the marketing function is likely to respond positively to this participatory form of control, wherein the top management provides procedural guidance and psychological support (Ramaswami, 1996).

Scholars have also recommended that the effects of process control be examined distinctly in terms of controlling activities and capabilities, instead of restricting it to a single construct (Challagalla and 
Shervani, 1996; Kohli et al., 1998). We, therefore, analyze and discuss how the control of marketing activities and marketing capabilities by the top management can each have a distinctive impact on the anomie in the marketing function.

\section{Control of marketing activities}

Control of marketing activities guides the marketing team by specifying the procedures that ought to be adopted for performing specific tasks (Jaeger and Baliga, 1985; Ramaswami, 1996). The prerequisites to the effective implementation of activity control include clearly defined procedures for the marketing processes and a strict adherence to those procedures (Ramaswami, 1996). For instance, top management may exercise activity control with the marketing function by setting procedures for boundary-spanning interactions (such as initiating business relationships with new clients), procedures for gathering and disseminating market research information, procedures for maintaining confidentiality of research participants, etc. Directing such activities would involve monitoring actual behaviors and rewarding (or punishing) performance of specified actions.

The assumption for activity control is that, based on past performance, if the prescribed procedures are followed correctly, the outcome should naturally follow. In the absence of an expected outcome, either more guidance is given or the procedures are adjusted accordingly (Anderson and Oliver, 1987). Thus by outlining the rules, boundaries, and procedures of the game, top management can reduce anxiety for the marketing team and have a positive impact on the environment of the marketing function, thereby reducing anomie. The respondents in our qualitative research affirmed the value of clear procedures and processes:

I think that definitely very formal processes, where you have written statements to data integrity, or, client privacy or customer privacy, [are] standards that [marketers will] adhere to.

-Marketing Manager, Marketing Research

We conjecture, however, that activity control reduces anomie in the marketing function only up to a point, beyond which more of activity control could in fact exacerbate anomie. Research on sales supervision suggests that under constant activity evaluation, employees could suffer a loss of selfdetermination and feel negative (Challagalla and Shervani, 1996). Our exploratory research also indicated a similar diminishing effect of activity control on anomie:

And so, I would copy [the supervisor] on emails, or I'd [relay] I just got off the phone with so and so, and this is what we talked about. Because those just made him feel like he was plugged in. It was ... a quantity issue, more than a quality issue. [After awhile] I made decisions ... just to [upset him] ... I was tempted to make decisions I wouldn't normally make. I was much more willing to bend some rules just to [upset] him.

-Marketing Manager, Marketing Research

Consequently, we propose that process control of marketing activities is likely to have a Ushaped relationship with anomie in the marketing function.

P3a: A U-shaped relationship exists between process control of marketing activities and anomie in the marketing function.

\section{Control of marketing capabilities}

Capabilities are essentially stable patterns of collective activities that allow firms to transform resource inputs effectively into superior value propositions (e.g., Zollo and Winter, 2002). Directing capabilities involves aiding the development of skills and abilities required for specified behavior (Challagalla and Shervani, 1996). Scholars have identified eight marketing capabilities specific to utilizing the classic marketing mix: product development, pricing, channel management, marketing communications, selling, market information management, marketing planning, and marketing implementation (Vorhies and Morgan, 2005). Top management can aid the development of these capabilities through periodic evaluations of skills, setting goals and objectives for skills and abilities, providing guidance and training for improving abilities, and rewarding (or punishing) for skill enhancement (or lack thereof) (Challagalla and Shervani, 1996). 
Using the anomie lens, we would expect that process control of capabilities influences the cultural structure of a social system. As the social system places greater emphasis on normative means and unambiguous procedures to attain cultural goals, enhanced capabilities to reach those goals raise the potential for goals-means congruence within the cultural structure of the social system. A greater emphasis on building capabilities through process control is likely to (a) enhance self-confidence and self-efficacy of marketing executives to meet or exceed corporate goals, (b) satisfy a marketing executive's intrinsic need for self-development as a professional (Challagalla and Shervani, 1996) and imbue skills that are transportable to other ventures should the executive decide to leave, (c) provide moral and developmental support to the marketing team, indicating the top management's care and concern about individual development, as was pointed out by one of our respondents:

And I've, I've watched this trend happen, in that if I focus on a [marketing unit] and their needs ... they see that you're overseeing them and so they want to strive to do well, and do the right thing

\section{-Regional Marketing Director, Healthcare}

Overall, process control of capabilities has the potential to balance the outcome expectations with the psychological and intellectual means to reach those goals, thereby reducing the likelihood of anomie to occur. Thus, we propose:

P3b: An inverse relationship exists between the level of process control used in managing marketing capabilities and the level of anomie in the marketing function.

\section{Process control and ethics codification}

We propose that codification of ethics in the marketing function moderates the impact of process control on anomie. Codification of ethics implies that there are clear guidelines, specific to the marketing function, on what are considered moral, ethical, and acceptable marketing practices and what are not. Scholars agree that although there is no clear consensus on what is ethical and what is not ethical in marketing practice (Robin and Reidenbach, 1987), marketing functions can be broadly categorized into those that codify their ethics and those that do not. Since sensitivity to ethics requires that marketing functions act out with carefully thought out rules of moral philosophy, marketing functions that do not codify their ethical guidelines are likely to be inconsistent in their ethical decision making. Codification brings consistency and unswerving guidelines that positively impact the environment of the marketing function by reducing ambiguity. Our respondents also noted that codification provides a common framework to guide behavior and provides a lens to mitigate disagreements:

I think it would keep people focused, on the ultimate end goal. It's really easy to get into the numbers game and the money games. But I think if we sit down and really think about our code of ethics ... that keeps you focused on more than the money.

\section{-Marketing Consultant, Software and E-Commerce}

Because, whereas I am a very ethical marketing director, the next person may not be. And so, [a marketing code of ethics] would be the company's way of stating this is what's important and valuable to us.

$$
\text { -Marketing Manager, Marketing Research }
$$

Using process control of both activities and capabilities for a marketing function that has high codification of ethics brings a synergy of dual forces that is likely to reduce anomie. A predominant focus on process control of marketing activities and capabilities creates a climate in which methods, procedures, and skills are emphasized as the primary drivers of firm success (Ramaswami, 1996). If this focus is coupled with a codified set of rules, then it is likely to lead to marketing decisions and actions that emphasize the appropriate means to achieve desired ends, rather than the ends themselves (Jaworski, 1988). In sociological terms, the greater the clarity regarding the normative means to attain cultural goals, the lesser the likelihood of incongruence between goals and means. Anomie is predicted to arise in social systems where the ethical codes are worded vaguely so that ethical transgressions are not looked upon as violations (Cohen, 
1993). If the ethical codes in the marketing function are worded imprecisely and loosely, it communicates to the marketing team that the top management is not serious about ramifications of ethically questionable behavior (Cohen, 1993). Hence, we posit:

P3c: The greater the codification of ethics in the marketing function, the higher the impact of process control (of activities and capabilities) in reducing anomie in the marketing function.

\section{Discussion}

The marketing function is often associated with unethical practices, given the exposure to environmental pressures inherent in its boundary-spanning role. While an array of theoretical frameworks addressing marketing ethical issues have been presented in the literature, scholars have called for further understanding of organizational levers that management can use to attenuate unethical practices. Heeding the call, we examine the inter-relationships between three sets of organizational factors - the environment of the marketing function, top management's control mechanisms, and contingency factors in the marketing function such as resource scarcity, power, and ethics codification - that impact ethical decision making. We argue that by understanding the sense of normlessness in the environment of the marketing function, through the theoretical notion of anomie (Merton, 1964, 1968), we can predict the propensity of unethical marketing practices to occur. We develop a conceptual model focusing on anomie in the marketing function, and argue how output and process control mechanisms employed by top management can have distinctive impacts on the extent of anomie. Additionally, we propose the moderating effects of three contingency variables - resource scarcity, power, and ethics codification - on the relationship between control mechanisms and anomie in the marketing function. Our conceptualization delivers a number of theoretical and managerial implications, to which we now turn.

\section{Theoretical implications}

We utilize the theoretical notion of anomie to illuminate conditions in the marketing function that encourage unethical marketing practices. While scholars have broadly addressed the role of anomie in ethics and in business crime (Cohen, 1993, 1995; Rosenbaum and Kuntze, 2003), we take it a step further and argue for: (a) the applicability of anomie in the context of marketing functions, (b) explicit linkages between structural factors, such as control mechanisms, and anomie in the marketing function, and (c) conditions in the marketing function such as resource scarcity, power, and ethics codification that impact the level of anomie. Our conceptualization lays the groundwork for investigating other organizational factors, such as leadership style or strategic orientations, which could impact anomie.

This conceptualization is also distinctive, in that we use a structural-level, sociological framework in Merton's (1968) theory of anomie. As noted earlier, prior studies have conducted examinations at the individual level (Caruana et al., 2001; Rosenbaum and Kuntze, 2003; Tsahuridu, 2006) and based their inquiries on psychological frameworks. In contrast, our examination is focused on the departmental milieu of the marketing function. This context also delineates our study from previous work that had studied anomie in settings such as retail businesses, undergraduate business schools, and workplaces in general (Caruana et al., 2000, 2001; Tsahuridu, 2006).

We also extend the body of theoretical literature on control mechanisms. Existing research on control mechanisms examines various approaches to set, monitor, and evaluate performance against a standard (Jaworski, 1988). We augment the research on control mechanisms by theorizing the unintended consequences of using output and process control. Although researchers in the past have evaluated the general dysfunctional consequences of using predominantly output control (Jaworski, 1988), control mechanisms have not been explicitly linked to the environment of the marketing function. We theorize that when top management picks output versus process control, it ends up creating very different structural conditions that have dissimilar impacts on the environment of the marketing function. Specifically, the predominant use of output control can create conditions that propagate anomie, and hence unethical marketing practices. Thus, we bring into focus the unintended effects of control mechanisms. 


\section{Future research directions}

The body of literature on anomie and control mechanisms would benefit from an empirical test of our conceptual framework. We recommend testing our proposed conceptual model through a cross-sectional survey with dual respondents (marketing managers and top management) in industries that are characterized with high competitive intensity and risk taking (such as those in SIC codes 35 and 36) as these are laden with internal and external pressures on the marketing team. Where questions dealing with the marketing function (i.e., anomie, power, resources, codification) should be addressed to the marketing managers, questions on control mechanisms should be directed at the top management of the company. A number of our constructs have a history of measures in the literature: Both Challagalla and Shervani (1996) and Ramaswami (1996) outline measures of output control and process control; similarly researchers have addressed power and influence of the marketing function (Homburg et al., 1999; Starr and Bloom, 1994). New measures can be developed for resource scarcity and codification of ethics based on theoretical literature. Scales capturing anomie from past research (Menard, 1995; Tsahuridu, 2006) can also be adapted to construct an anomie scale for our context. The following firm characteristics should be controlled for when testing our model: firm size, firm age, industry type, and level of competitive intensity in the industry.

\section{Managerial implications}

Corporate managements, by and large, are aware of the fact that a large number of ethical problems in business arise in marketing, particularly in the buyer/ seller dyad (Vitell, 2003). Given the increasing popularity of outsourcing, the number of business networks and alliances between marketers and their constituents is only likely to further increase. While these new interactions create dynamic new roles and relationships for marketers, they also heighten the potential for ethical pitfalls. To either reduce or eliminate ethical transgressions by the marketing team, both the top management and marketing executives need to be aware of the organizational conditions that encourage unethical practices. Our model provides multiple directions to managers wanting to get a grip on such underlying factors.

First, top management needs to be cognizant of the unintended consequences of using output versus process control to manage the marketing function. The impact of a particular control mechanism extends beyond just governance and supervision. Control mechanisms signal expectations, explicitly or implicitly approve of goals and procedures, shape the environment of the marketing function, and thus lay the groundwork for ethical or unethical practices to follow. When top management predominantly employs output control mechanisms, it puts an emphasis on bottom-line objectives. This leads to the marketing function's environment being characterized by the management's constant focus, monitoring, and evaluation of prized organizational outcomes. Such an environment is likely to be marked by many demands on the marketing function, such as weekly sales forecasts demanded by top management, frequent calls for forecast revisions regardless of the availability of any new data or market insight, and frequent submission of action plans for cutting marketing costs. To operate and be rewarded in this environment, marketing executives must singularly focus on efficient goal achievement. This may often involve incrementally disregarding normative procedures. From innocuously over-forecasting expenses in the marketing budget (e.g., as a contingency to meet profit goals) to inflating projected sales of a new product to ensure capital investment, even the most conscientious marketer faces a war of attrition within this environment. Ultimately, an environmental imbalance is created within the marketing function and it claims its share of ethical casualties.

Second, the use of process control mechanisms paired with a code of marketing ethics provides proactive safeguards against unethical marketing practices. By prescribing, monitoring, and evaluating marketing processes; and developing a code of ethics specific to marketing, top management can take the ambiguity out of the environment of the marketing function. We acknowledge that firms may employ a combination or hybrid of the two control mechanisms. However, our aim here is to stress the need to identify the managerial levers that promote a balanced marketing environment. Having a code of ethics specific to the marketing 
function, along with routine monitoring of the environment, would serve as valuable inputs for managerial decision making regardless of the control mechanism(s) employed.

Finally, both the top management and marketing managers need to be sensitive to environmental conditions that are symptomatic of anomie. Typical individual psychological responses to anomie include a sense of futility, alienation, and powerlessness (Cohen, 1993). Managers should be cognizant of such symptoms and realize that unless structural changes are made, individuals are likely to feel discouraged and lose their motivation to act ethically. As we argue, one of the ways to attenuate anomie is to re-visit the control mechanisms in practice.

Both scholars and practitioners have observed that marketing as a function is losing its influence with the top-management teams (Kumar, 2004). Increasingly, it is more likely to find marketing functions being controlled by top executives from other functions, such as finance, who do not share the same understanding for the processes, pressures, and ethics of marketing. Therefore, it is critical for the top management to understand the consequences of their decisions on how to manage marketing functions. Top management's decisionmaking process must include an assessment of the potential second-order effects of control mechanisms. The firm is best served when equilibrium exists between the organizationally prized outcomes and the normative means to achieve them.

\section{Note}

1. For an exhaustive summary of articles detailing ethics within specific marketing domains see Tsalikis and Fritzsche (1989).

\section{References}

Agnew, R., F. T. Cullen, V. S. Burton, Jr., T. D. Evans and R. G. Dunaway: 1996, "A New Test of Classic Strain Theory," Justice Quarterly 13(4), 681-704.

Akaah, I. P. and E. A. Riordan: 1990, "The Incidence of Unethical Practices in Marketing Research: An Empirical Investigation," Journal of the Academy of Marketing Science 18(2), 143-152.

Anderson, P. F.: 1982, "Marketing, Strategic Planning and the Theory of the Firm," Journal of Marketing 46(2), 15-26.
Anderson, E. and R. L. Oliver: 1987, "Perspectives on Behavior-Based Versus Outcome-Based Sales-force Control Systems," Journal of Marketing 51(4), 76-88.

Baumer, E. P.: 2007, “Untangling Research Puzzles in Merton's Multilevel Anomie Theory," Theoretical Criminology 11(1), 63-93.

Baumhart, R. C.: 1961, “How Ethical are Businessmen?" Harvard Business Review 39(4), 6-12, 19, 156-176.

Berkowitz, L.: 1962, Aggression: A Social Psychological Analysis (McGraw-Hill, New York).

Blankenship, A. B.: 1964, "Some Aspects of Ethics in Marketing Research," Journal of Marketing Research 1(2), 26-31.

Bommer, M., C. Gratto, J. Gravander and M. Tuttle: 1987, "A Behavioral Model of Ethical and Unethical Decision Making," Journal of Business Ethics 6(4), 265-280.

Brenner, S. N. and E. A. Molander: 1977, "Is the Ethics of Business Changing?," Harvard Business Review 55(1), 57-71.

Burawoy, M.: 1991, Ethnography Unbound: Power and Resistance in the Modern Metropolis (University of California Press, Berkeley).

Burton, V., Jr. and F. T. Cullen: 1992, “The Empirical Status of Strain Theory," Journal of Crime and Justice 2, $1-30$.

Caruana, A., B. Ramaseshan and M. T. Ewing: 2000, "The Effect of Anomie on Academic Dishonesty Among University Students', International Journal of Educational Management 14(1), 23-30.

Caruana, A., B. Ramaseshan and M. T. Ewing: 2001, "Anomia and Deviant Behaviour in Marketing: Some Preliminary Evidence," Journal of Managerial Psychology 16(5), 322-338.

Challagalla, G. N. and T. A. Shervani: 1996, "Dimensions and Types of Supervisory Control: Effects on Salesperson Performance and Satisfaction," Journal of Marketing 60(1), 89-105.

Cloward, R. A. and L. E. Ohlin: 1960, Delinquency and Opportunity (Free Press, New York).

Cohen, A.: 1965, "The Sociology of the Deviant Act: Anomie Theory and Beyond," American Sociological Review 30(1), 5-14.

Cohen, D. V.: 1993, “Creating and Maintaining Ethical Work Climates: Anomie in the Workplace and Implications for Managing Change," Business Ethics Quarterly 3, 343-358.

Cohen, D. V.: 1995, "Ethics and Crime in Business Firms: Organizational Culture and the Impact of Anomie," in F. Adler and W. S. Laufer (eds.), The Legacy of Anomie Theory (Transaction, New Brunswick, NJ), pp. 183-206. 
Creswell, J. W. and V. L. Plano Clark: 2007, Designing and Conducting Mixed Methods Research (Sage Publications, Thousand Oaks, CA).

Deshpande, R. and F. E. Webster, Jr.: 1989, “Organizational Culture and Marketing: Defining the Research Agenda," Journal of Marketing 53(1), 3-15.

Durkheim, E.: [1897]/1951, Suicide (Free Press, New York).

Featherstone, R. and M. Deflem: 2003, "Anomie and Strain: Context and Consequences of Merton's Two Theories," Sociological Inquiry 73(4), 471-489.

Ferrell, O. C. and L. G. Gresham: 1985, “A Contingency Framework for Understanding Ethical Decision Making in Marketing," Journal of Marketing 49(3), 87-96.

Fullilove, M. T., V. He'on, W. Jimenez, C. Parsons, L. L. Green and R. E. Fullilove: 1998, "Injury and Anomie: Effects of Violence on an Inner-City Community," American Journal of Public Health 88(6), 924-927.

Ghoshal, S. and P. Moran: 1996, "Bad for Practice: A Critique of the Transaction Cost Theory," Academy of Management Review 21, 13-47.

Giacobbe, R. W. and M. N. Segal: 2000, "A Comparative Analysis of Ethical Perceptions in Marketing Research: U.S.A. vs. Canada," Journal of Business Ethics 27(3), 229-245.

Hickson, D. J., C. R. Hinings, C. A. Lee, R. E. Schneck and J. M. Pennings: 1971, "A Strategic Contingencies' Theory of Intraorganizational Power," Administrative Science Quarterly 16(2), 216-229.

Homburg, C., J. P. Workman, Jr. and H. Krohmer: 1999, "Marketing's Influence Within the Firm," Journal of Marketing 63(2), 1-17.

Hunt, S. D. andA.Z.Vasquez-Parraga: 1993, “Organizational Consequences, Marketing Ethics, and Salesforce Supervision," Journal of Marketing Research 30(1), 78-90.

Hunt, S. D. and S. Vitell: 1986, "A General Theory of Marketing Ethics," Journal of Macromarketing 6(Spring), 5-16.

Hunt, S. D., L. B. Chonko and J. B. Wilcox: 1984, "Ethical Problems of Marketing Researchers," Journal of Marketing Research 21(3), 309-324.

Hunt, S. D., V. R. Wood and L. B. Chonko: 1989, “Corporate Ethical Values and Organizational Commitment in Marketing," Journal of Marketing 53(3), 79-90.

Jackson, E. F. and P. J. Burke: 1965, "Status and Symptoms of Stress: Additive and Interaction Effects," American Sociological Review 30(4), 556-564.

Jaeger, A. M. and B. R. Baliga: 1985, “Control Systems and Strategic Adaptation: Lessons from the Japanese Experience," Strategic Management Journal 6(2), 115-134.
Jaworski, B. J.: 1988, “Toward a Theory of Marketing Control: Environmental Context, Control Types, and Consequences," Journal of Marketing 52(3), 23-39.

Jones, T. M.: 1991, “Ethical Decision Making by Individuals in Organizations: An Issue-Contingent Model," Academy of Management Review 16(2), 366-395.

Kohli, J. and B. Jaworski: 1990, “Market Orientation: The Construct, Research Propositions, and Managerial Implications," Journal of Marketing 54(2), 1-18.

Kohli, A. K., T. A. Shervani and G. N. Challagalla: 1998, "Learning and Performance Orientation of Salespeople: The Role of Supervisors," Journal of Marketing Research 35(2), 263-274.

Krause, M. S.: 2002, Contemporary White Collar Crime Research: A Survey of Findings Relevant to Personnel Security the Personnel Security Managers' Research Program. http://www.navysecurity.navy. mil/white $\% 20$ collar\%20crime.pdf .

Kumar, N.: 2004, Marketing as Strategy: Understanding the CEO's Agenda for Driving Growth and Innovation (Harvard Business School Press, Boston, MA).

Laczniak, E. and P. Murphy: 1991, "Fostering Ethical Marketing Decisions," Journal of Business Ethics 10(4), 259-271.

Lee, M. R. and J. P. Bartkowski: 2004, “Love Thy Neighbor? Moral Communities, Civic Engagement, and Juvenile Homicide in Rural Areas," Social Forces 82(3), 1001-1035.

Leigh, J. H. and P. E. Murphy: 1999, “The Role of Formal Policies and Informal Culture on Ethical Decision Making by Marketing Managers," Research in Marketing 15, 69-99.

Lund, D. B.: 2000, “An Empirical Examination of Marketing Professionals' Ethical Behavior in Differing Situations," Journal of Business Ethics 24(4), 331-342.

MacIver, R. M.: 1950, The Ramparts We Guard (Macmillan, New York, NY).

Mansfield, P.: 2004, "Anomie and Disaster in Corporate Culture: The Impact of Mergers and Acquisitions on the Ethical Climate of Marketing Organizations," Marketing Management Journal 14(2), 88-99.

Menard, S.: 1995, “A Developmental Test of Mertonian Anomie Theory," Journal of Research in Crime and Delinquency 32, 136-174.

Merton, R. K.: 1964, “Anomie, Anomia, and Social Interaction: Contexts of Deviant Behavior," in M. B. Clinard (ed.), Anomie and Deviant Behavior: A Discussion and Critique (Free Press of Glencoe, New York).

Merton, R. K.: 1968, Social Theory and Social Structure (Free Press, New York), p. 702.

Messner, S. F.: 2003, “An Institutional-Anomie Theory of Crime: Continuities and Elaborations in the Study of 
Social Structure and Anomie," Cologne Journal of Sociology and Social Psychology 43, 93-109.

Messner, S. F. and R. Rosenfeld: 1997, "Political Restraint of the Market and Levels of Criminal Homicide: A Cross-National Application of Institutional Anomie Theory," Social Forces 75(4), 1393-1416.

Moustakas, C.: 1994, Phenomenological Research Methods (Sage Publications, Thousand Oaks, CA).

Murphy, P. E.: 1995, “Corporate Ethics Statements: Current Status and Future Prospects," Journal of Business Ethics 14(9), 727-740.

Nantel, J. and W. A. Weeks: 1996, "Marketing Ethics: Is There more to It than the Utilitarian Approach?," European Journal of Marketing 30(5), 9-19.

Orru, M.: 1987, Anomie: History and Meanings (Allen and Unwin, Boston), p. 210.

Ouchi, W. G.: 1977, “The Relationship Between Organizational Structure and Organizational Control," $A d-$ ministrative Science Quarterly 22(1), 95-113.

Poveda, T. G.: 1994, Rethinking White Collar Crime (Prager Publishers, Westport CT).

Ramaswami, S. N.: 1996, "Marketing Controls and Dysfunctional Employee Behaviors: A Test of Traditional and Contingency," Journal of Marketing 60(2), 105-120.

Ramaswami, S. N.: 2002, "Influence of Control Systems on Opportunistic Behaviors of Salespeople: A Test of Gender Differences," Journal of Personal Selling and Sales Management 22(3), 173-188.

Robertson, D. C. and E. Anderson: 1993, "Control System and Task Environment Effects on Ethical Judgment: An Exploratory Study of Industrial Salespeople," Organization Science 4(4), 617-644.

Robin, D. P. and R. E. Reidenbach: 1987, "Social Responsibility, Ethics, and Marketing Strategy: Closing the Gap Between Concept and Application," Journal of Marketing 51(1), 44-58.

Roma'n, S. and J. L. Munuera: 2005, “Determinants and Consequences of Ethical Behaviour: An Empirical Study of Salespeople," European Journal of Marketing 39(5-6), 473-495.

Rosenbaum, M. S. and R. Kuntze: 2003, “The Relationship Between Anomie and Unethical Retail Disposition," Psychology and Marketing 20(12), 1067-1093.

Rust, R. T., T. Ambler, G. S. Carpenter, V. Kumar and R. K. Srivastava: 2004, "Measuring Marketing Productivity: Current Knowledge and Future Directions," Journal of Marketing 68(4), 76-89.

Schein, E. H.: 1984, "Coming to a New Awareness of Organizational Culture," Sloan Management Review 25(2), 3-16.
Schneider, B and J. Rentsch: 1988, "Managing Climates and Cultures: A Future's Perspective," in J. Hage (ed.), Futures of Organizations (Lexington Books, Lexington, MA).

Smith, E. R.: 1998, “Mental Representation and Memory," in D. T. Gilbert, S. T. Fiske and G. Lindzey (eds.), The Handbook of Social Psychology (Oxford University Press, Oxford), pp. 391-445.

Smith, C. N. and E. Cooper-Martin: 1997, "Ethics and Target Marketing: The Role of Product Harm and Consumer Vulnerability," Journal of Marketing 61(3), 1-20.

Srivastava, R. K., T. A. Shervani and L. Fahey: 1998, “Market-Based Assets and Shareholder Value: A Framework for Analysis," Journal of Marketing 62(1), 2-18.

Srole, L.: 1956, "Social Integration and Certain Corollaries: An Exploratory Study," American Sociological Review 21(6), 709-716.

Starr, J. R. G. and P. N. Bloom: 1994, “The Power Relationships of Brand Managers," Marketing Letters 5(3), 211-223.

Stinchcombe, A. L.: 1964, Rebellion in High School (Quadrangle Books, Chicago), p. 240.

Trevino, L. K., K. D. Butterfield and D. L. McCabe: 1998, "The Ethical Context in Organizations: Influences on Employee Attitudes and Behaviors," Business Ethics Quarterly 8(3), 447-476.

Trostel, A. O. and M. L. Nichols: 1982, "Privately-Held and Publicly-Held Companies: A Comparison of Strategic Choices and Management Processes," Academy of Management Journal 25(1), 47-62.

Tsahuridu, E. E.: 2006, “Anomie and Ethics at Work," Journal of Business Ethics 69, 163-174.

Tsalikis, J. and D. J. Fritzsche: 1989, “Business Ethics: A Literature Review with a Focus on Marketing Ethics," Journal of Business Ethics 8(9), 695-743.

Tybout, A. M. and G. Zaltman: 1974, "Ethics in Marketing Research: Their Practical Relevance," Journal of Marketing Research 11(4), 357-368.

Vardi, Y.: 2001, "The Effects of Organizational and Ethical Climates on Misconduct at Work," Journal of Business Ethics 29(4), 325-337.

Vardi, Y. and V. Wiener: 1996, "Misbehavior in Organizations: A Motivational Framework," Organization Science 7(2), 151-165.

Vorhies, D. and N. A. Morgan: 2005, “Benchmarking Marketing Capabilities for Sustainable Competitive Advantage," Journal of Marketing 69(1), 80-94.

Verbeke, W., C. Ouwerkerk and E. Peelen: 1996, “Exploring the Contextual and Individual Factors on Ethical Decision Making of Salespeople," Journal of Business Ethics 15(11), 1175-1187. 
Vittell, S. J.: 2003, “Consumer Ethics Research: Review, Synthesis and Suggestions for the Future," Journal of Business Ethics 43(1-2), 33-47.

Workman, J. P., Jr., C. Homburg and K. Gruner: 1998, "Marketing Organization: An Integrative Frame- work of Dimensions and Determinants," Journal of Marketing 62(3), 21-41.

Zollo, M. and S. G. Winter: 2002, “Deliberate Learning and the Evolution of Dynamic Capabilities," Organization Science 13(3), 339-353. 